\title{
Clinical and radiological characteristics of e-cigarette or vaping product use associated lung injury
}

\author{
Ambika G. Chidambaram ${ }^{1}$ - Rebecca A. Dennis ${ }^{2,3}$ • David M. Biko ${ }^{2,3} \cdot$ Marcus Hook $^{2}$ • Julian Allen ${ }^{1,3}$. \\ Jordan B. Rapp ${ }^{1,2,3}$
}

Received: 18 April 2020 / Accepted: 19 May 2020 / Published online: 28 May 2020

(C) American Society of Emergency Radiology 2020

\begin{abstract}
Purpose E-cigarette or vaping product use associated lung injury (EVALI) has received national attention as an epidemic resulting in cases of significant morbidity and mortality. We aim to present the clinical and imaging findings in adolescents with pulmonary symptoms from suspected EVALI.

Methods Chest radiographs and CTs of adolescents ( $<19$ years) with acute pulmonary symptoms and history of vaping were reviewed by two radiologists in consensus. Clinical presentation and laboratory data were derived from the electronic medical records including pulmonary function tests (PFTs).

Results Eleven patients were identified ( 9 male, mean 16.6 years). The most common presentation was progressive, subacute respiratory distress with abdominal pain. All but one of the patients tested positive for tetrahydrocannabinol. Chest radiograph features were notable for interstitial pattern of opacities $(91 \%)$ and basilar abnormalities $(82 \%)$. CT features were notable for ground-glass opacities (89\%), interstitial opacities (78\%), and subpleural sparing (67\%). Eight patients underwent PFTs. Six had diffusing capacity measurement, which demonstrated impaired diffusion in $3(50 \%)$. All patients received supportive treatment with supplemental oxygen and corticosteroids.

Conclusion Adolescents with suspected EVALI commonly present with subacute respiratory distress with abdominal pain. Imaging findings include ground-glass opacities, subpleural sparing, and basilar opacities, most consistent with organizing pneumonia or hypersensitivity pneumonitis. Recognition of the common imaging findings may have significant patient management implications, especially if the diagnosis is not suspected clinically. The lung function effects of vaping are consistent with mildly reduced airflow, which improves on follow-up testing, and reduced diffusion capacity, which, concerningly, does not improve.
\end{abstract}

Keywords EVALI $\cdot$ Chest $\cdot$ Adolescents $\cdot$ PFTs

Meetings This paper was accepted for presentation at the Society of Pediatric Radiology (SPR) 2020 in Miami, FL originally scheduled for May 12th 2020.

Jordan B. Rapp

rappj@email.chop.edu

1 Department of Pulmonology, Children's Hospital of Philadelphia, Philadelphia, PA, USA

2 Department of Radiology, Children's Hospital of Philadelphia, 3401 Civic Center Blvd, 3NW40, Philadelphia, PA 19104, USA

3 University of Pennsylvania, Perelman School of Medicine, Philadelphia, PA, USA

\section{Introduction}

Lung injury related to the use of electronic nicotine and marijuana delivery devices recently and markedly spiked over the several months in late 2019. Per the CDC morbidity and mortality publication as of February 2020, there have been over 2800 reported cases of hospitalized e-cigarette or vaping product use associated lung injury (EVALI) in the USA with 86 deaths, an increase from only 215 reported cases with 1 death as recently as August 2019, while reaching a peak incidence in September 2019 [1-3]. Fifteen percent of these patients are under 18 years old.

In this most recent $\mathrm{CDC}$ report, $82 \%$ of patients who had an EVALI had used a tetrahydrocannabinol (THC)-containing 
product. Approximately 1 in 4 adolescent e-cigarette users admit to vaping with cannabis [4]. There has also been a strong association with vitamin $\mathrm{E}$ contamination contributing to the lung injury, detected in bronchial alveolar lavage (BAL) in all 51 of the sampled cases, while other tested oils were present in only two cases [5].

The majority of patients have been reported to present acutely with constitutional symptoms (fever, malaise, fatigue, headache), gastrointestinal symptoms (nausea, vomiting, abdominal pain, weight loss, anorexia), and respiratory symptoms (cough, chest pain, shortness of breath) $[1,6,7]$. Given the presentation being very similar to a viral prodrome, for example influenza or COVID-19 infection, EVALI is a diagnosis of exclusion [1]. The acuity of presentation has been reported to be variable, but the majority tend to present within 7 days of onset of symptoms [8].

Despite availability of electronic nicotine delivery systems (ENDS) in the USA since 2007, initial reports of acute inhalation-related injuries were limited with the first case report described in 2013 [9]. A case of EVALI associated with cannabis oil was first reported in an adult patient in 2017 [10] and described as pulmonary hemorrhage and organizing pneumonia on CT and biopsy evaluations. Since then, EVALI has been documented in the radiologic literature as a variety of case reports and case series with descriptions varying. Imaging appearances on radiographs and CTs have been likened to hypersensitivity pneumonitis (HP) [11], organizing pneumonia (OP) $[7,10,12,13]$, acute alveolar hemorrhage [11, 14], diffuse alveolar damage of ARDS $[8,15,16]$, and an early single case of acute eosinophilic pneumonia (AEP) [9]. While lipid laden macrophages have been seen on BAL [17], there have not yet been any reported $\mathrm{CT}$ findings of lipoid pneumonia in the literature.

\section{Materials and methods}

\section{Patient selection}

Our study was approved by our Institutional Review Board and was HIPAA compliant. A single institution retrospective study was performed utilizing the hospital and pulmonology department databases to identify all adolescent patients $(<19$ years old) with a history of frequent vaping with clinically suspected EVALI after presenting with respiratory distress between January 2019 and December 2019.

Imaging along with clinical, laboratory, and bronchoscopic data was reviewed along with clinical symptoms at the time of presentation.

\section{Imaging review and analysis}

Chest radiographs and chest $\mathrm{CT}$ s were reviewed in consensus by two pediatric chest radiologists (DMB-10 years of experience, and JBR -3 years of experience). The first radiograph associated with the current admission was interrogated. Each chest radiograph was evaluated for presence of interstitial or alveolar opacities and/or consolidation. Distribution of disease, symmetry of disease, and presence of pleural effusions or pneumothorax were also assessed.

For evaluation of the chest CTs, a more detailed assessment was performed. Ground-glass opacities; interstitial opacities; tree-in-bud opacities; centrilobular nodules; consolidation; presence of macroscopic focal fat; and/or mosaic attenuation were evaluated. Distribution was determined as bilaterally symmetric/asymmetric, as apical or basilar, and for the presence of subpleural sparing. Evaluation of the airway included assessment of bronchiectasis, airway impaction, or peribronchial thickening. The pleura was also evaluated for effusions or pneumothorax.

\section{Clinical and pathology review}

A retrospective chart review was performed by a senior pediatric pulmonology fellow and experienced pediatric pulmonologist (AGC and JA) on all 11 patients who were admitted with EVALI. Information regarding demographics, clinical presentation at admission, hospital course, treatment, pulmonary function testing, bronchoalveolar lavage findings, and vaping product use was collected. Due to the lack of clinical guidelines in the treatment of EVALI at that time, the clinical practice varied between patients. Clinical notes from followup appointments were also reviewed if available. The collected data were analyzed using descriptive statistics.

\section{Results}

Eleven patients were identified, all of whom presented to the emergency department for evaluation. Although the inclusion criteria was from January 2019 to December 2019, all cases occurred in the late summer and fall, between August 2019 and November 2019 (Table 1).

All 11 patients underwent chest radiography at time of presentation to the emergency room. Chest radiographs were performed in both the anterior posterior (AP) and lateral in 9 of 11 patients, and only the AP projection in the remainder of the patients. Ten $(91 \%)$ of these patients underwent a subsequent chest CT within 3 days of presentation (range $0-3$, mode: same day, mean $<1$ days). Half $(5 / 10)$ of the CTs were performed at an outside institution with the patient thereafter transferred to our institution for tertiary care, resulting in various techniques utilized. Most chest CTs were performed with 
Table 1 Demographics, clinical characteristics, treatment, and clinical course

\begin{tabular}{|c|c|}
\hline \multicolumn{2}{|l|}{ Demographics } \\
\hline Median age at presentation (range)-year & $16(15-18)$ \\
\hline Male sex-no./total no. $(\%)$ & 9/11 (82) \\
\hline \multicolumn{2}{|l|}{ Race—no./total no. $(\%)$} \\
\hline White & $10 / 11(91)$ \\
\hline Other & $1 / 11(9)$ \\
\hline History of asthma & $6 / 11(55)$ \\
\hline \multicolumn{2}{|l|}{ E-cigarette reported use - no./total no. (\%) } \\
\hline THC only & $10 / 11(91)$ \\
\hline Nicotine only & $8 / 11(73)$ \\
\hline Both THC and nicotine & $7 / 11(64)$ \\
\hline Other (CBD, cigarette smoking) & $5 / 11(45)$ \\
\hline Admission to intensive care unit - no./total no. (\%) & $5 / 11(45)$ \\
\hline Median length of hospital stay (range) - days & $5(2-10)$ \\
\hline \multicolumn{2}{|l|}{ Symptoms at presentation $—$ no./total no. $(\%)$} \\
\hline Respiratory related symptom & $10 / 11(91)$ \\
\hline Gastrointestinal related symptom & $11 / 11(100)$ \\
\hline Constitutional symptoms & $11 / 11(100)$ \\
\hline \multicolumn{2}{|l|}{ Initial laboratory results - no./total no. $(\%)$} \\
\hline White blood cell count $(>11,000 / \mu \mathrm{L})$ & $7 / 11(64)$ \\
\hline C-reactive protein $>0.9 \mathrm{mg} / \mathrm{dL}$ & $6 / 6(100)$ \\
\hline Erythrocyte sedimentation rate $>30 \mathrm{~mm} / \mathrm{h}$ & $8 / 8(100)$ \\
\hline \multicolumn{2}{|l|}{ Respiratory viral panel PCR—no./total no. (\%) } \\
\hline Rhinovirus positive & $3 / 11(27)$ \\
\hline Negative & 8/11 (73) \\
\hline \multicolumn{2}{|l|}{ Urine drug screen-no./total no. $(\%)$} \\
\hline THC positive & 10/11 (91) \\
\hline
\end{tabular}

$P C R$, polymerase chain reaction; $T H C$, tetrahydrocannabinol; $C B D$, cannabidiol

intravenous contrast (7/10). Low-dose techniques were utilized in examination performed at our institution. No patient has had follow-up CT examination to date.

Patients ranged in age from 15 to 18 years with a mean of 16.6 years at presentation. Nine of the eleven $(82 \%)$ patients were male, and $91 \%$ (10/11) of the patients were white. A total of $55 \%(6 / 11)$ of the patients had a prior diagnosis of asthma at the time of presentation. Ninety-one percent (10/11) reported that they had vaped THC, $73 \%(8 / 11)$ vaped nicotine, and $64 \%(7 / 11)$ vaped both, at the time of presentation. Fortyfive percent of the $(5 / 11)$ patients had reported that they vaped other products such as cannabidiol (CBD), and two patients smoked combustible cigarettes.

All of the eleven patients had gastrointestinal and constitutional symptoms, and $91 \%$ of the (10/11) patients had respiratory symptoms at the time of presentation. Sixty-four percent had leukocytosis and 73\% (8/11) had elevated inflammatory markers. All of our patients underwent respiratory viral
PCR testing, and 3/11 were positive for rhinovirus (Table 1). However, this was not considered to be the sole or a prominent reason for their clinical symptoms by the clinical team in accordance with the CDC case definitions [8].

Sixty-four percent (7/11) received oxygen supplementation and $45 \%(5 / 11)$ received non-invasive positive pressure ventilation. Eighty-two percent (9/11) of the patients were treated with antibiotics for possible community-acquired pneumonia, and almost all, 91\% (10/11), were treated with varying doses of glucocorticoids. All 11 patients were admitted, while $45 \%$ $(5 / 11)$ required admission to the intensive care unit, and the other patients were admitted to the general pediatric, pulmonary, or adolescent inpatient service. The median length of stay in the hospital was 5 days (range 2-10 days) (Table 1 ).

Initial chest radiographs were remarkable in that all cases demonstrated bilateral opacities, symmetric in 5/11. All cases were described as having an interstitial opacities, and $82 \%$ (9/11) had a basilar predominance of abnormalities (Fig. 1a). Five of the chest radiographs demonstrated alveolar opacities, but this was a less of a prominent finding in all but one case. Consolidations were not seen on any initial radiograph. No pleural effusions or pneumothoraces were seen, though one case had pneumomediastinum at presentation.

If performed, all patients also had positive imaging findings on CT. CT scans of the chest demonstrated a predominance of ground-glass opacities in all but one case. Two cases (20\%) had subtle centrilobular ground-glass nodules at the apices. Six of ten demonstrated interstitial opacities described as a minor finding. None of the ten were described as having tree-in-bud opacities or mosaic attenuation. No cases had lowdensity opacities to suggest the presence of macroscopic focal lipids. Four (40\%) had mild bronchial wall thickening. None were seen to have bronchiectasis or bronchial impaction. Distribution of disease was described as symmetric in 6 of 10. An apical to basilar predominance of disease distribution was seen in 8 of 10 , while 7 of 10 had subpleural sparing ( 7 of the 9 of those with ground-glass opacities), and 4 with reverse halo sign of ground-glass opacities (Figs. 2 and 3) (Table 2).

The only patient (patient 7) who presented with an EVALI who did not test positive for THC had imaging findings that differed substantially. Multifocal dense consolidative opacities and small effusions were seen bilaterally on CT, not present in any of the other cases. Spirometry was not performed on this patient.

None of the other 9 cases had pleural effusions or pneumothorax. One pneumomediastinum was observed initially (Fig. 3). A second patient developed pneumomediastinum at a later date. Of note, neither of these patients were undergoing nor subsequently required mechanical ventilation.

Among the patients who underwent spirometry and diffusing capacity during their hospital stay and on a mean followup of 46 days, mean FEV1 increased from 81 (z-score = 1.99) to $99 \%(z=-0.1)$. Among the patients who underwent 

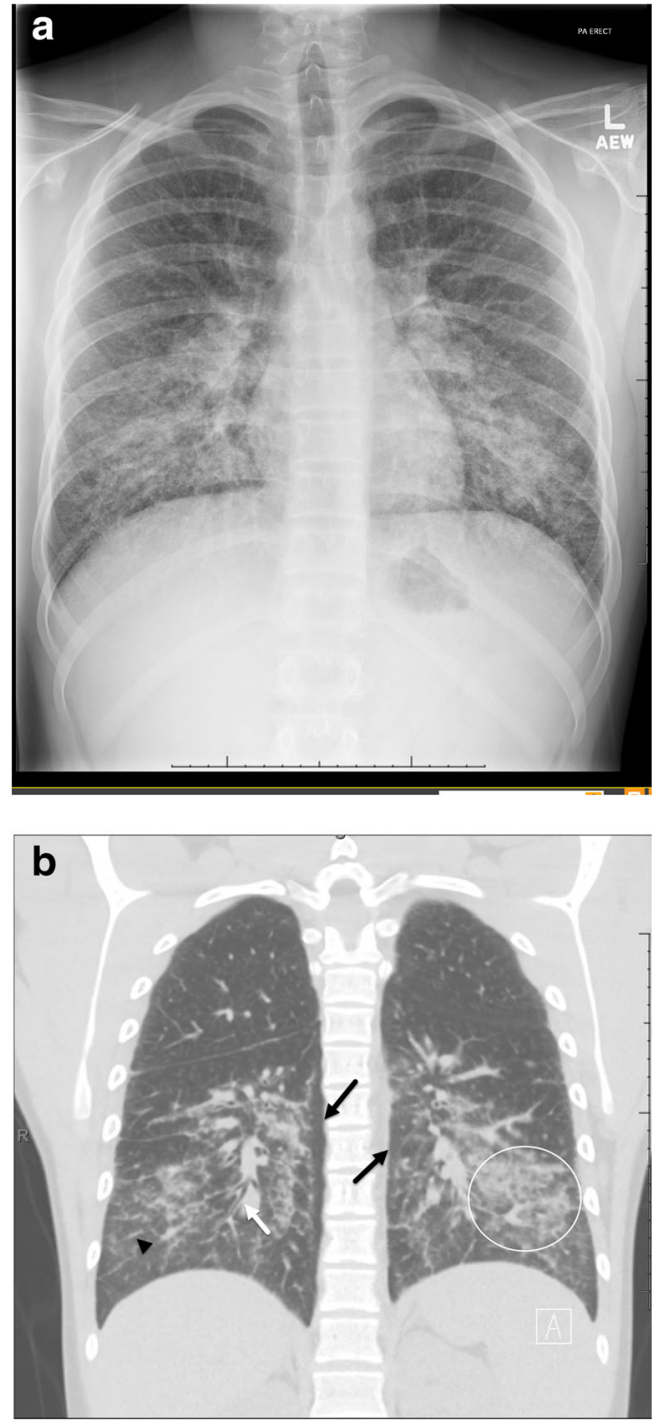

Fig. 1 a A 16 year-old male (patient 6) presents with cough, fever, and emesis. Chest radiograph on day of presentation demonstrates bilateral symmetric interstitial opacities in a basilar predominance distribution. $\mathbf{b}$ Coronal non-contrast CT chest in lung windows from the same day demonstrated bilateral, symmetric ground-glass (circle) and interstitial opacities (arrowhead) in an apical to basilar distribution with subpleural sparing (black arrows). Bronchial wall thickening is also seen (white arrow)

measurement of diffusion capacity, the mean diffusing capacity of the lung for carbon monoxide/alveolar volume (DLCO/VA) measured was $78 \%(\mathrm{z}=-1.68)$ during admission and $74.8 \%(z=-1.99)$ on follow-up.

One patient underwent flexible bronchoscopy and bronchoalveolar lavage a month after discharge, as his sputum was positive for mycobacterium avium complex infection. The bronchoalveolar lavage did not grow non-tuberculous mycobacteria; however, it showed neutrophilia and lipid droplets in approximately 40$50 \%$ of the macrophages in oil red $\mathrm{O}$ stain. Since this patient did not have other findings to suggest mycobacterium avium complex infection, a decision was made to not treat him with antinon-tuberculous mycobacterial therapy.

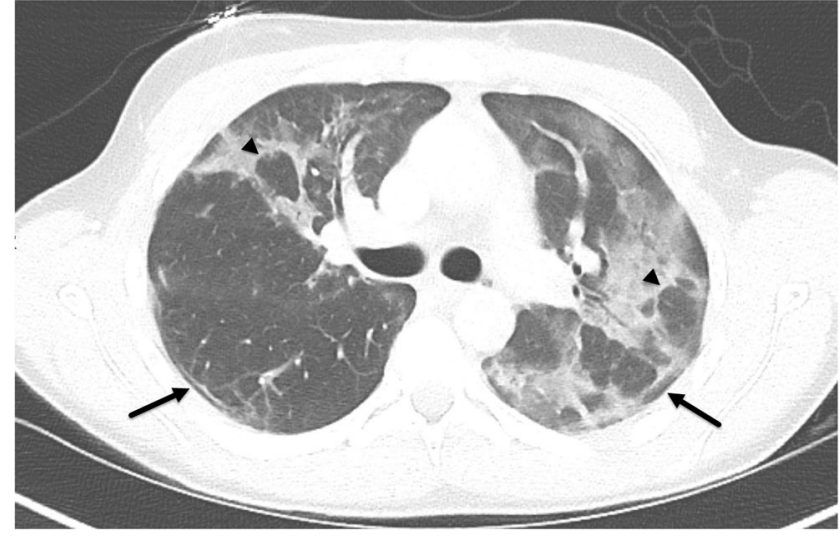

Fig. 2 A17-year-old male (patient 3) with past medical history of asthma presented to the emergency department with increased work of breathing and hypoxia. Axial contrast-enhanced CT chest in lung windows demonstrates asymmetric bilateral ground-glass opacities with subpleural sparing (arrows) and reverse halo signs (arrowheads)

\section{Discussion}

The response of the lung to acute inhalation injury is limited despite many potential causes. Vaping poses a quandary as to the exact offending agent, with cannabinoid compounds or vitamin $\mathrm{E}$ having been raised as possibilities. These agents are related to alteration of initially licit products $[1,4]$. The resultant effect on the lungs is also not clear to our knowledge, as this may be related to an inhaled oil, toxin, or perhaps allergen.

Our cohort consisted exclusively of teenagers. The clinical presentation was similar to the data presented by Layden et al. [8], and most of our patients vaped THC products. While a prior report of patients with EVALI has shown reduced lung

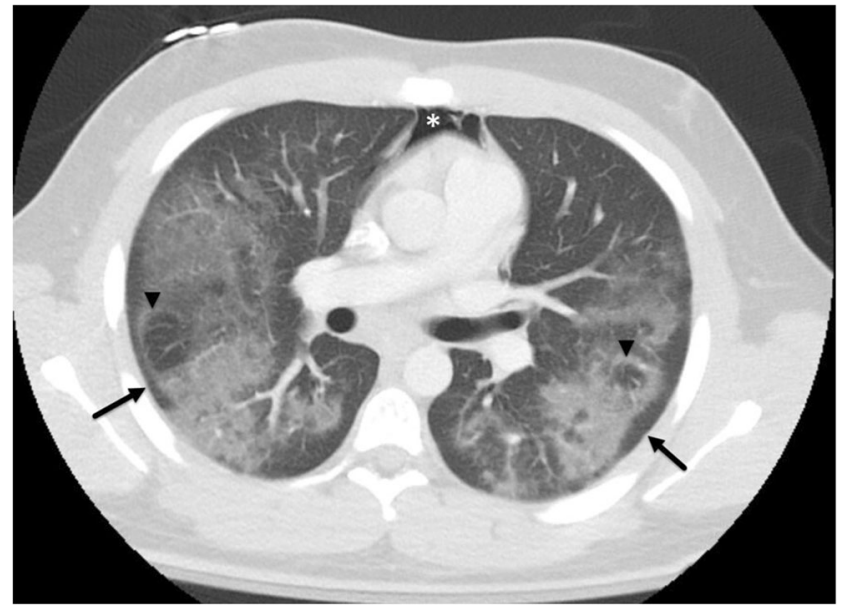

Fig. 3 A 17-year-old male (patient 11) with past medical history of asthma presented to the emergency department with respiratory failure, fever, and vomiting. Axial contrast-enhanced CT chest in lung windows demonstrates similar findings as in Fig. 2 with bilateral symmetric groundglass opacities with subpleural sparing (arrows) and reverse halo signs seen bilaterally (arrow heads). Pneumomediastinum is also present (asterisk) 
Table 2 Individual CT findings

\begin{tabular}{|c|c|c|c|c|c|c|c|c|c|c|}
\hline $\begin{array}{l}\text { Patient } \\
\text { no. }\end{array}$ & $\begin{array}{l}\text { Age and } \\
\text { gender }\end{array}$ & $\begin{array}{l}\text { Apical } \\
\text { basilar } \\
\text { gradient }\end{array}$ & Symmetry & $\begin{array}{l}\text { Subpleural } \\
\text { sparing }\end{array}$ & GGO & $\begin{array}{l}\text { Interstitial } \\
\text { opacities }\end{array}$ & Consolidation & $\begin{array}{l}\text { Low- } \\
\text { density } \\
\text { lipoid }\end{array}$ & $\begin{array}{l}\text { Bronchial wall } \\
\text { thickening }\end{array}$ & $\begin{array}{l}\text { Pleural/mediastinal } \\
\text { abnormality }\end{array}$ \\
\hline 1 & $16 \mathrm{~F}$ & Yes & No & No & Yes & Yes & No & No & No & No \\
\hline 2 & $16 \mathrm{M}$ & Yes & Yes & Yes & Yes & Yes & No & No & Yes (diffuse) & No \\
\hline 3 & $17 \mathrm{M}$ & No & No & Yes & Yes & Yes & No & No & No & No \\
\hline 4 & $15 \mathrm{M}$ & Yes & No & Yes & Yes & Yes & No & No & No & No \\
\hline 6 & $16 \mathrm{M}$ & Yes & Yes & Yes & Yes & Yes & No & No & Yes (basilar) & No \\
\hline 7 & $17 \mathrm{M}$ & Yes & Yes & No & No & No & Yes (multifocal) & No & No & $\begin{array}{l}\text { Small bilateral } \\
\text { effusions }\end{array}$ \\
\hline 8 & $17 \mathrm{M}$ & Yes & Yes & Yes & Yes & No & No & No & No & No \\
\hline 9 & $17 \mathrm{~F}$ & No & Yes & No & Yes & Yes & No & No & Yes (basilar) & No \\
\hline 10 & $17 \mathrm{M}$ & Yes & No & Yes & Yes & No & No & No & Yes (diffuse) & No \\
\hline 11 & $17 \mathrm{M}$ & Yes & Yes & Yes & Yes & No & No & No & No & Pneumomediastinum \\
\hline
\end{tabular}

Patient 5 was excluded as CT was not performed

$M$, male; $F$, female; $G G O$, ground-glass opacities

Distribution noted by parentheses

function and diffusing capacity during admission [7], in this study, we have shown a discrepancy between spirometry and diffusing capacity on follow-up. In comparing pulmonary function testing in the hospital and at 46-day follow-up, FEV1 was mildly reduced and increased by $18 \%$, but DLCO/VA was mildly to moderately reduced and did not improve. This impaired diffusion capacity, and the lack of improvement on follow-up, indicates damage to the bloodgas barrier and is consistent with the ground-glass and interstitial infiltrates seen on CT scan.

The overall imaging appearances of our cohort demonstrate a pattern that is similar to HP and OP. This is most evident in that there was a predominance of ground-glass opacities with an apical to basilar gradient of worsening disease and striking subpleural sparing seen in most cases with several demonstrating reverse halo sign. These are in line with several other recent studies also demonstrating subpleural sparing $[7,8$, $13,18,19]$. The only patient who tested negative for THC and had multifocal consolidations was felt to represent a case of true multifocal pneumonia rather than EVALI.

Findings similar to OP has been described in EVALI patients $[7,13]$. While the imaging appearances of OP can vary, the predominant finding of the diffuse form of OP is peripheral and peribronchial opacities [20]. Subpleural sparing similar to the majority of our cases has been described in OP as well. A classically described relatively specific though nonsensitive finding in OP is a reverse halo opacity, as was seen in several of our patients [20].

HP can be categorized as acute, subacute, or chronic, and requires an antigen exposure. Like OP, the radiographic appearance of HP can vary widely. The most prominent finding is typically extensive ground-glass opacities. In addition, centrilobular ground-glass nodules and mosaic attenuation may appear in the acute form [21]. The "headcheese sign" of HP represents a combination of ground-glass and mosaic attenuations. Of these classically described patterns, only the dominant ground-glass opacities are seen in our cohort. Interestingly, HP can also mimic OP or has features of OP, resulting in a confusing and overlapping CT appearance [21, 22].

Lipoid pneumonia is often attributed to the inadvertent inhalation of macroscopic oils and fats resulting in a specific CT finding of low-density areas of consolidation corresponding to macroscopic fat [23]. No cases in our cohort or in the publish literature has had this $\mathrm{CT}$ finding. A less-specific though common CT finding of lipoid pneumonia of bilateral segmental or lobar ground-glass opacities is common in our cases. While initial reports described EVALI as a potential exogenous lipoid pneumonia, they were reported as secondary to only BAL findings with lipid laden macrophages, as also seen in our single case which underwent BAL. These microscopic lipids are not resolvable by $\mathrm{CT}$ and may not be related to macroscopic fat ingested described with lipoid pneumonia. Furthermore, two recent reviews of biopsied patients with EVALI did not reveal any lipids [24, 25].

Lastly, none of our subjects were tested for the novel coronavirus, SARS-CoV2, since all imaging studies were done before December 2019 and clinical testing for the novel coronavirus was not yet available in Philadelphia at that time. Since the first case of COVID-19, the illness caused by SARS-CoV2 was not described in the USA until January 20,2020 [26], we do not believe that any of our subjects 
had COVID-19. However it is noteworthy that some of the radiological abnormalities of EVALI and COVID-19 can overlap [27-29]. COVID-19 features deemed typical by consensus reporting $[30,31]$ include bilateral lower lobe predominant ground-glass opacities that can be subpleural. However, subpleural sparing is not described as a typical feature, a differentiating feature of EVALI. Furthermore, COVID-19 may appear as OP later in the disease course, similar to EVALI. In addition to both EVALI and COVID-19 resulting in respiratory symptoms, other constitutional symptoms are seen in both conditions, most notably abdominal pain, further clouding the picture. With many overlapping features between these two entities, COVID-19 should now be considered in the differential diagnosis of EVALI, particularly in atypical or indeterminant COVID-19 features, with history and laboratory abnormalities also aiding in attempt to distinguish these entities.

\section{Conclusion}

Vaping-related lung injury can be recognized based on clinical history and radiologic appearance. The lung function effects of vaping are consistent with mildly reduced airflow, which improves on follow-up testing, and reduced diffusion capacity, which, concerningly, does not improve. Classifying the CT findings as a specific previously defined entity is extremely difficult due to the current limited pathologic information of EVALI, though an imaging pattern has emerged similar to that of organizing pneumonia and hypersensitivity pneumonitis. Bilateral ground-glass opacities worse at the base with subpleural sparing are common presenting CT signs. Without other known causes for such a CT appearance, such as the novel coronavirus, the evaluation for EVALI should be explored.

\section{Compliance with ethical standards}

Our study was approved by our Institutional Review Board and was HIPAA compliant.

Conflict of interest The authors declare that they have no conflict of interest.

\section{References}

1. Chatham-Stephens K, Roguski K, Jang Y et al (2019) Characteristics of hospitalized and nonhospitalized patients in a nationwide outbreak of E-cigarette, or Vaping, Product UseAssociated Lung Injury - United States, November 2019. MMWR Morb Mortal Wkly Rep 68:1076-1080. https://doi.org/ 10.15585/mmwr.mm6846e1

2. Krishnasamy VP, Hallowell BD, Ko JY et al (2020) Update: characteristics of a nationwide outbreak of E-cigarette, or Vaping,
Product Use-Associated Lung Injury - United States, August 2019-January 2020. MMWR Morb Mortal Wkly Rep 69:90-94. https://doi.org/10.15585/mmwr.mm6903e2

3. Ellington S, Salvatore PP, Ko J et al (2020) Update: product, substance-use, and demographic characteristics of hospitalized patients in a nationwide outbreak of E-cigarette, or Vaping, Product UseAssociated Lung Injury — United States, August 2019-January 2020. MMWR Morb Mortal Wkly Rep 69:44 49. https://doi.org/ 10.15585/mmwr.mm6849e1

4. Trivers KF, Phillips E, Gentzke AS, Tynan MA, Neff LJ (2018) Prevalence of cannabis use in electronic cigarettes among US youth. JAMA Pediatr 172:1097-1099. https://doi.org/10.1001/ jamapediatrics.2018.1920

5. Blount BC, Karwowski MP, Shields PG, Morel-Espinosa M, Valentin-Blasini L, Gardner M, Braselton M, Brosius CR, Caron KT, Chambers D, Corstvet J, Cowan E, de Jesús VR, Espinosa P, Fernandez C, Holder C, Kuklenyik Z, Kusovschi JD, Newman C, Reis GB, Rees J, Reese C, Silva L, Seyler T, Song MA, Sosnoff C, Spitzer CR, Tevis D, Wang L, Watson C, Wewers MD, Xia B, Heitkemper DT, Ghinai I, Layden J, Briss P, King BA, Delaney LJ, Jones CM, Baldwin GT, Patel A, Meaney-Delman D, Rose D, Krishnasamy V, Barr JR, Thomas J, Pirkle JL, Lung Injury Response Laboratory Working Group (2020) Vitamin E acetate in bronchoalveolar-lavage fluid associated with EVALI. N Engl J Med 382:697-705. https://doi.org/10.1056/NEJMoa1916433

6. Kligerman S, Raptis C, Larsen B, Henry TS, Caporale A, Tazelaar H, Schiebler ML, Wehrli FW, Klein JS, Kanne J (2020) Radiologic, pathologic, clinical, and physiologic findings of Electronic Cigarette or Vaping Product Use-associated Lung Injury (EVALI): evolving knowledge and remaining questions. Radiology 294:491-505. https://doi.org/10.1148/radiol. 2020192585

7. Thakrar PD, Boyd KP, Swanson CP, Wideburg E, Kumbhar SS (2020) E-cigarette, or vaping, product use-associated lung injury in adolescents: a review of imaging features. Pediatr Radiol 50:338344. https://doi.org/10.1007/s00247-019-04572-5

8. Layden JE, Ghinai I, Pray I, et al (2019) Pulmonary illness related to e-cigarette use in Illinois and Wisconsin - preliminary report. $\mathrm{N}$ Engl J Med 1-14. https://doi.org/10.1056/nejmoa1911614

9. Thota D, Latham E (2014) Case report of electronic cigarettes possibly associated with eosinophilic pneumonitis in a previously healthy active-duty sailor. J Emerg Med 47:15-17. https://doi.org/ 10.1016/j.jemermed.2013.09.034

10. He T, Oks M, Esposito M, Steinberg H, Makaryus M (2017) “Treein-Bloom": severe acute lung injury induced by vaping cannabis oil. Ann Am Thorac Soc 14:468-470. https://doi.org/10.1093/ntr/ ntw194.Pepper

11. Henry TS, Kligerman SJ, Raptis CA et al (2020) Imaging findings of vaping-associated lung injury. AJR Am J Roentgenol 214:1-8

12. Khan MS, Khateeb F, Akhtar J, Khan Z, Lal A, Kholodovych V, Hammersley J (2018) Organizing pneumonia related to electronic cigarette use: a case report and review of literature. Clin Respir J 12: 1295-1299. https://doi.org/10.1111/crj.12775

13. Artunduaga M, Rao D, Friedman J, et al (2020) Pediatric chest radiographic and CT findings of Electronic Cigarette or Vaping Product Use-associated Lung Injury (EVALI). Radiology 192778. https://doi.org/10.1148/radiol.2020192778

14. Agustin M, Yamamoto M, Cabrera F, Eusebio R (2018) Diffuse alveolar hemorrhage induced by vaping. Case Rep Pulmonol 2018: 1-3. https://doi.org/10.1155/2018/9724530

15. Abeles M, Popofsky S, Wen A, et al (2019) Vaping-associated lung injury caused by inhalation of cannabis oil. Pediatr Pulmonol 1-3. https://doi.org/10.1002/ppul.24579

16. Sakla NM, Gattu R, Singh G, Sadler M (2019) Acute respiratory distress syndrome. Emerg Radiol. https://doi.org/10.1017/ 9781316443415.047 
17. Viswam D, Trotter S, Burge PS, Walters GI (2018) Respiratory failure caused by lipoid pneumonia from vaping e-cigarettes. BMJ Case Rep 2018:1-4. https://doi.org/10.1136/bcr-2018-224350

18. Conuel JE, Chieng HC, Fantauzzi J et al (2019) Cannabinoid oil vaping associated lung injury and its radiographic appearance. Am J Med. https://doi.org/10.1016/j.amjmed.2019.10.032

19. Triantafyllou GA, Tiberio PJ, Zou RH, Lamberty PE, Lynch MJ, Kreit JW, Gladwin MT, Morris A, Chiarchiaro J (2019) Vapingassociated acute lung injury: a case series. Am J Respir Crit Care Med 200:1430-1431. https://doi.org/10.1164/rccm.201909-1809le

20. Kligerman SJ, Franks TJ, Galvin JR (2013) From the Radiologic Pathology Archives. Organization and fibrosis as a response to lung injury in diffuse alveolar damage, organizing pneumonia, and acute fibrinous and organizing pneumonia. Radiographics 33:1951-1976

21. Elicker BM, Jones KD, Henry TS, Collard HR (2016) Multidisciplinary approach to hypersensitivity pneumonitis. J Thorac Imaging 31:92-103. https://doi.org/10.1097/RTI. 0000000000000186

22. Silva CIS, Churg A, Müller NL (2007) Hypersensitivity pneumonitis: spectrum of high-resolution CT and pathologic findings. Am J Roentgenol 188:334-344. https://doi.org/10.2214/AJR.05.1826

23. Betancourt SL, Martinez-Jimenez S, Rossi SE, Truong MT, Carrillo J, Erasmus JJ (2010) Lipoid pneumonia: spectrum of clinical and radiologic manifestations. Am J Roentgenol 194:103-109. https://doi.org/10.2214/AJR.09.3040

24. Cecchini M, Boland J, Bois M et al (2019) Real-time digital surveillance of vaping-induced pulmonary disease. $N$ Engl J Med 381: 1778-1780. https://doi.org/10.1056/NEJMc1912818

25. Mukhopadhyay S, Mehrad M, Dammert P, et al (2019) Lung biopsy findings in severe pulmonary illness associated with e-cigarette use (vaping). Am J Clin Pathol 1-10. https://doi.org/10.1093/ajcp/ aqz182

26. Holshue ML, DeBolt C, Lindquist S, Lofy KH, Wiesman J, Bruce H, Spitters C, Ericson K, Wilkerson S, Tural A, Diaz G, Cohn A, Fox LA, Patel A, Gerber SI, Kim L, Tong S, Lu X, Lindstrom S, Pallansch MA, Weldon WC, Biggs HM, Uyeki TM, Pillai SK (2020) First case of 2019 novel coronavirus in the United States.
N Eng1 J Med 382:929-936. https://doi.org/10.1056/ NEJMoa2001191

27. Foust AM, Winant AJ, Chu WC, et al (2020) Pediatric SARS, H1N1, MERS, EVALI, and now coronavirus disease (COVID19) pneumonia: what radiologists need to know. AJR Am J Roentgenol 1-9. https://doi.org/10.2214/AJR.20.23267

28. Rubin GD, Haramati LB, Kanne JP, Schluger NW, Yim JJ, Anderson DJ, Altes T, Desai SR, Goo JM, Inoue Y, Luo F, Prokop M, Richeldi L, Tomiyama N, Leung AN, Ryerson CJ, Sverzellati N, Raoof S, Volpi A, Martin IBK, Kong C, Bush A, Goldin J, Humbert M, Kauczor HU, Mazzone PJ, Remy-Jardin M, Schaefer-Prokop CM, Wells AU (2020) The role of chest imaging in patient management during the COVID-19 pandemic: a multinational consensus statement from the Fleischner Society. Radiology 201365:201365. https://doi.org/10.1148/radiol. 2020201365

29. Gorbalenya AE, Baker SC, Baric RS, et al (2020) Severe acute respiratory syndrome-related coronavirus: the species and its viruses-a statement of the Coronavirus Study Group. https://doi. org/10.1101/2020.02.07.937862

30. Foust AM, Phillips GS, Chu WC, Daltro P, Das KM, Garcia-Peña P, Kilborn T, Winant AJ, Lee EY (2020) International Expert Consensus Statement on Chest Imaging in Pediatric COVID-19 Patient management: imaging findings, imaging study reporting and imaging study recommendations. Radiol Cardiothorac Imaging 2:e200214. https://doi.org/10.1148/ryct.2020200214

31. Simpson S, Kay FU, Abbara S, et al (2020) Radiological Society of North America expert consensus statement on reporting chest. CT findings related to COVID-19. Endorsed by the Society of Thoracic Radiology, the American College of Radiology, and RSNA. J Thorac Imaging 00:1. https://doi.org/10.1097/rti. 0000000000000524

Publisher's note Springer Nature remains neutral with regard to jurisdictional claims in published maps and institutional affiliations. 